\title{
O Olhar de Diferentes Regiões do Brasil na Reumatologia Atual
}

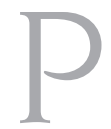
rezados colegas e amigos, novamente fazemos chegar até vocês uma nova edição da Revista Brasileira de Reumatologia (RBR), sempre com assuntos atuais e com artigos de elevado conteúdo científico. Os dois primeiros artigos originais são importantes estudos para o nosso meio e para a consolidação de novos conceitos sobre o papel do anti-CCP na gravidade e no diagnóstico da artrite reumatóide de São Luis ${ }^{(1,2)}$. O terceiro artigo original trata da interessante comparação dos critérios de classificação de artrite psoriásica realizado por Marques e cols., de Recife ${ }^{(3)}$. O primeiro artigo de revisão envolve um tema de grande interesse que é a avaliação das evidências para o uso de antiinflamatórios tópicos em osteoartrite de joelho, realizada por Pereira e cols. ${ }^{(4)}$. $\mathrm{O}$ segundo artigo de revisão versa sobre os estudos da relação entre colágeno $\mathrm{V}$ e o desenvolvimento de doenças auto-imunes e na proposta de conhecimento do modelo animal de esclerose sistêmica ${ }^{(5)}$.

Ficamos contentes de também poder lhes trazer a apresentação de três excelentes relatos de casos que foram avaliados pelo nosso corpo editorial e reunidos nesta edição, todos acompanhados por precisa e informativa revisão de cada um dos assuntos. São eles: o relato de caso de sacroiliíte de Silva e cols., de Campo Grande, Mato Grosso ${ }^{(6)}$; outro sobre comprometimento auditivo em pacientes com granulomatose de Wegener, de Gomides e cols., de Belo Horizonte, Minas Gerais $^{(7)}$; e o inovador e ilustrativo caso do uso tópico

\section{REFERÊNCIAS}

1. Silva AF, Matos AN, Lima MAS e cols: Associação do Anticorpo Anticitrulina e Gravidade da Artrite Reumatóide. Rev Bras Reumatol 46: 165-73, 2006.

2. Silva AF, Matos AN, Lima MAS e cols: Valor Diagnóstico do Anticorpo Antipeptídeo Citrulinado Cíclico na Artrite Reumatóide. Rev Bras Reumatol 46: 174-80, 2006.

3. Marques CDL, Cantagrel A, Cavalcanti F, Duarte ALBP: Estudo Comparativo de Quatro Critérios de Classificação para Artrite Psoriásica. Rev Bras Reumatol 46: 181-7, 2006.

4. Pereira HLA, Ribeiro SLE, Ciconelli RM: Tratamento com Antiinflamatórios Tópicos na Osteoartrite de Joelho. Rev Bras Reumatol 46: 188-93, 2006. de pimecrolimus em caso de paciente com lesão cutânea de LES refratária ao uso sistêmico de corticosteróide e azatioprina, enviado pelos sempre colaborativos Rangel e cols., de Salvador, Bahia ${ }^{(8)}$.

Fomos ainda contemplados com um artigo bastante didático sobre a artro-ressonância do ombro na instabilidade anterior, ricamente ilustrado, da nossa sempre presente e curiosa vinheta imagenológica apresentada pelos colegas da UNIFESP, Artur Fernandes e Jamil Natour.

Brindamos ainda, como sempre, na pausa entre consultas, a prova de título de especialista, importante passo ao ingresso dos mais novos associados à nossa prestimosa Sociedade Brasileira de Reumatologia (SBR).

$\mathrm{Na}$ seção de atualizações, a preciosa colaboração de Dawton Torigoe e Ieda Laurindo com importante seleção de artigos discutindo os aspectos mais atuais do tratamento da artrite reumatóide.

Nosso sempre lembrado agradecimento aos colegas que colaboram com a RBR e aos membros do corpo editorial que tanto têm prestigiado e contribuído com o excelente nível cientifico alcançado pela nossa revista. Continuamos contando com o esforço conjunto de todos, colaboradores, consultores e leitores.

Boa leitura.

Lais V. Lage e Roger A. Levy Editores Científicos da RBR

5. Oliveira CC, Teodoro WR, Velosa APP, Yoshinari NH: Autoimunidade e Colágeno V. Rev Bras Reumatol 46: 194-8, 2006.

6. Silva EK, Guedes-Barbosa LS, Batista MCP: Sacroileíte Bilateral por Criptococos: Relato de um Caso e Revisão de Literatura. Rev Bras Reumatol 46: 225-30, 2006.

7. Gomides APM, Rosário EJ, Borges HM, Vignoli MA, Pádua PM, Sousa RCA: Perda Auditiva Neurossensorial em Pacientes com Granulomatose de Wegener: Relato de Três Casos e Revisão de Literatura. Rev Bras Reumatol 46: 234-8, 2006.

8. Rangel LV, Santiago JM, Souza JCC, Nascimento LFL, Santiago MB: Terapia Tópica com Pimecrolimus em Lesão Cutânea Refratária de Lúpus Eritematoso Sistêmico. Rev Bras Reumatol 46: 230-4, 2006. 